\title{
Overview of the STAT-3 signaling pathway in cancer and the development of specific inhibitors (Review)
}

\author{
YUCHEN GU ${ }^{1,2}$, IMRAN SHAIR MOHAMMAD ${ }^{3}$ and ZHE LIU $^{1,2}$ \\ ${ }^{1}$ Department of Pharmacy, The First Affiliated Hospital of Bengbu Medical College; \\ ${ }^{2}$ College of Pharmacy, Bengbu Medical College, Bengbu, Anhui $233000 ;{ }^{3}$ School of Pharmaceutical Sciences, \\ Sun Yat-Sen University, Guangzhou, Guangdong 510006, P.R. China
}

Received July 20, 2019; Accepted December 19, 2019

DOI: $10.3892 / \mathrm{ol} .2020 .11394$

\begin{abstract}
Signal transducer and activator of transcription (STAT) proteins represent novel therapeutic targets for the treatment of cancer. In particular, STAT-3 serves critical roles in several cellular processes, including the cell cycle, cell proliferation, cellular apoptosis and tumorigenesis. Persistent activation of STAT-3 has been reported in a variety of cancer types, and a poor prognosis of cancer may be associated with the phosphorylation level of STAT-3. Furthermore, elevated STAT-3 activity has been demonstrated in a variety of mammalian cancers, both in vitro and in vivo. This indicates that STAT-3 serves an important role in the progression of numerous cancer types. A significant obstacle in developing STAT-3 inhibitors is the demonstration of the antitumor efficacy in in vivo systems and the lack of animal models for human tumors. Therefore, it is crucial to determine whether available STAT-3 inhibitors are suitable for clinical trials. Moreover, further preclinical studies are necessary to focus on the impact of STAT-3 inhibitors on tumor cells. When considering STAT-3 hyper-activation in human cancer, selective targeting to these proteins holds promise for significant advancement in cancer treatment. In the present study, advances in our knowledge of the structure of STAT-3 protein and its regulatory mechanisms are summarized. Moreover, the STAT-3 signaling pathway and its critical role in malignancy are discussed, in addition to the development of STAT-3 inhibitors in various cancer types.
\end{abstract}

Correspondence to: Dr Zhe Liu, Department of Pharmacy, The First Affiliated Hospital of Bengbu Medical College, 287 Changhuai Road, Bengbu, Anhui 233000, P.R. China

E-mail: 117915493@qq.com

Key words: signal transducer and activator of transcription 3, STAT-3 inhibitor, signaling pathway, small molecule inhibitor, cancer

\section{Contents}

1. Introduction

2. STAT-3 structure

3. STAT-3 signal transduction cascade

4. Target genes regulated by STAT-3

5. Advances in antitumor therapeutics targeting STAT-3

6. Conclusions

\section{Introduction}

Signal transducer and activator of transcription (STAT) proteins are a class of transcription factor that are activated by cytokines, growth factors and other peptide ligands. STATs are activated by tyrosine phosphorylation in response to diverse cytokine signals in the cytoplasm. Following activation, the STAT proteins translocate to the nucleus, binding their specific targets and serving as transcription factors (1-4). STATs influence numerous physiological processes, including cell proliferation, apoptosis, division and differentiation (5). In healthy cells, the activation of STATs is tightly regulated to prevent uncontrolled gene expression; however, prolonged activation of STATs in cancer cells may result in significant adverse effects, such as drug resistance and poor prognosis $(5,6)$. In humans, the STAT family comprises seven proteins, including STAT-1, $-2,-3,-4,-5 \mathrm{~A},-5 \mathrm{~B}$ and -6 , and the genes encoding the STAT family are located on chromosomes 2 (STAT-1 and -4), 12 (STAT-2 and -6) and 17 (STAT-3, -5A and -5B) (7). Among the seven members, STAT-3 and -5 exhibit the strongest association with tumor progression. Persistent activation of STAT-3 or STAT-5 (particularly STAT-3) regulates a variety of functions, including proliferation, cell cycle progression, apoptosis, angiogenesis and immune evasion (8-10). Consequently, STAT-3 mainly contributes to tumor proliferation and survival owing to its role in stromal cells, including immune cells recruitment in the tumor microenvironment to promote tumor growth, and is, therefore, recognized as a promising target for cancer therapy (11-16).

Previous studies have demonstrated that DNA methylation and chromatin modulation may also be regulated by STAT-3 via epigenetic mechanisms $(17,18)$. Moreover, STAT-3 has been recognized as a potent immune checkpoint regulator for 
multiple antitumor immune response pathways $(12,13)$. Despite the plethora of evidence implicating STAT-3 in the progression of several types of cancer and indicating it as an ideal target for cancer therapy, there is still no clinical drug available that directly targets STAT-3 (19). Thus, a novel small molecule able to directly target STAT-3 may represent a promising novel STAT-3 inhibitor. Notably, STAT-3 is highly complex in its diverse biological functions, as well as its various activators. Therefore, further investigations into STAT-3 biology and signaling pathways are particularly important.

\section{STAT-3 structure}

STAT-3 is comprised of $\sim 800$ amino acids, and its relative mass is $92 \mathrm{kDa}$; it has several conserved functional domains, including N-terminal, coiled-domain, DNA-binding domain (DBD), Src-homology-2 (SH-2) domain and transactivation (TA) domain (20-22). DBD has specificity with certain regions of DNA, allowing STAT-3 to bind downstream of the target gene-promoter element to induce the expression of target genes. The SH-2 domain participates in phosphorylation of tyrosine residues, facilitating protein-protein interactions with tyrosine-phosphorylated proteins (23). Furthermore, the SH-2 domain is critical in the formation of the STAT-3 dimer (the region that STAT-3 binds to in order to activate receptors). In between the DBD and SH-2 domain there is a linker protein that mediates the stability of DNA binding and assembly of the transcriptional body (24). The TA domain contains one tyrosine phosphorylation site (Yyr705) and one serine phosphorylation site (Ser727). During STAT-3 activation, tyrosine and serine residues are phosphorylated by upstream kinases and recognized by the SH-2 domain (25), as indicated in Fig. 1.

However, it has been demonstrated that STAT-3 contains three different isomers: The full-length $\alpha$ form, and two shorter isoforms, $\beta$ and $\gamma$, which are the result of mRNA splicing and proteolysis, respectively. STAT-3 $\alpha$ primarily participates in cell proliferation and transformation, while STAT- $3 \beta$ regulates cell differentiation mediated by granulocyte colony-stimulating factor (G-CSF) and lacks a serine phosphorylation site (26). Activated STAT-3 $\gamma$ has been identified in differentiated neutrophils and does not contain a transactivation domain $(27,28)$. A previous study also suggested that these isoforms may exert a dominant-negative effect on their full-length counterparts (29).

\section{STAT-3 signal transduction cascade}

Transient STAT3 activation is a key determinant of tissue integrity restoration, wound healing and immune response resolution, given its critical biological functions (30). STAT-3 is heavily regulated to ensure transient activation under standard conditions. To mediate this process, three classes of proteins located upstream of STAT-3 influence negative regulation of its activation, including tyrosine phosphatases, protein inhibitors of activated STATs (PIAS) and suppressors of cytokine signaling (SOCS) (31). Tyrosine phosphatases downregulate Janus kinase (JAK)/STAT signaling via dephosphorylation of STAT and its upstream kinases (32). It has been reported that the protein tyrosine phosphatase receptor T specifically dephosphorylates the Tyr705 residue in the TA domain of STAT-3 (32). The PIAS family comprises four members: PIAS-1, -3 , -x and -y (33). Of these, PIAS-3 is associated with STAT-3 inhibition via blocking its binding to DNA, recruiting co-repressors or serving as SUMOylation E3 ligases (34-36). The SOCS family of proteins, also known as cytokine-induced SH-2-containing proteins, inhibit STAT-3 binding and decrease JAK activity via competitive binding to phosphorylated tyrosine residues on activated cytokine receptors or JAK (19). As the receptor lacks its own enzymatic activity, STAT-3 is primarily activated via the JAK-dependent pathway (37).

The JAK/STAT-3 pathway is typically considered the most crucial signaling pathway in the activation of STAT-3 (18). Notably, interleukin (IL)-6 is the most well-characterized upstream cytokine, which binds specifically to membrane-bound receptors in the JAK/STAT-3 pathway (38-40). IL- 6 binds IL- 6 receptor- $\alpha$ on the cell surface, inducing conformational changes and resulting in the formation of a homodimer and heterodimer. This initiates the activation of JAK, followed by recruitment and activation of cytosolic STAT-3 (18). Consequently, activated STAT-3 translocates to the nucleus and binds to its target gene (Fig. 2).

Certain other IL family members can induce STAT-3 translocation to the nucleus, including IL-11 and -31, leukemia inhibitory factor, ciliary neurotrophic factor and oncostatin $\mathrm{M}$. Moreover, it has been reported that IL-6-class cytokines serve crucial roles in the progression of numerous tumor types, including breast, lung and prostate cancer, and also multiple hematopoietic malignancies (41-50). Although other IL-6-class cytokines contribute to tumor development, IL-6 is considered the most significant regulator of the JAK/STAT-3 pathway in tumors. Furthermore, certain reports have demonstrated that IL-6 is regulated by specific oncogenes, such as breakpoint cluster region-ABL protooncogene and RAS $(51,52)$. Recent studies have reported that IL-6 promotes cell migration via the induction of epithelial-mesenchymal transition (EMT), and IL-6-mediated EMT in breast cancer may be a consequence of STAT-3 activation (53-55). These findings indicate that STAT-3 may represent a target that can inhibit tumor development mediated by the aforementioned oncogenes (53).

G-protein-coupled receptors (GPCRs) are not traditional receptors in the JAK/STAT-3 pathway; however, several findings suggested that GPCRs may be a STAT-3 activator contributing to tumor progression (56). Sphingosine-1-phosphate receptor-1 (S1PR-1) is a type of GPCR that is upregulated in malignant, immune and endothelial cells. Previously, S1PR-1 was revealed to be associated with tumor cell survival and resistance to chemotherapy in a variety of cancer cells (57-62). Moreover, sphingosine-1-phosphate receptor 1 (S1PR-1) activates STAT-3 via JAK-2, resulting in the cyclical upregulation of S1PR-1 expression (63). In general, toll-like receptors (TLRs) participate in innate immune system responses, connecting specific immunity to non-specific immunity. Nevertheless, recent studies have demonstrated the crucial role of TLRs in the activation of STAT-3 and tumor progression. It has been reported that TLR-4 induces STAT-3 activation via upregulation of IL-6 and microRNA (miR)-21, resulting in the neoplastic progression of colon cancer in vivo (64). Furthermore, TLR-2, -7 and -9 were all identified to correlate with STAT-3 activation and tumor progression (65-67). These findings indicate that GPCRs and TLRs activate the JAK/STAT-3 signaling 


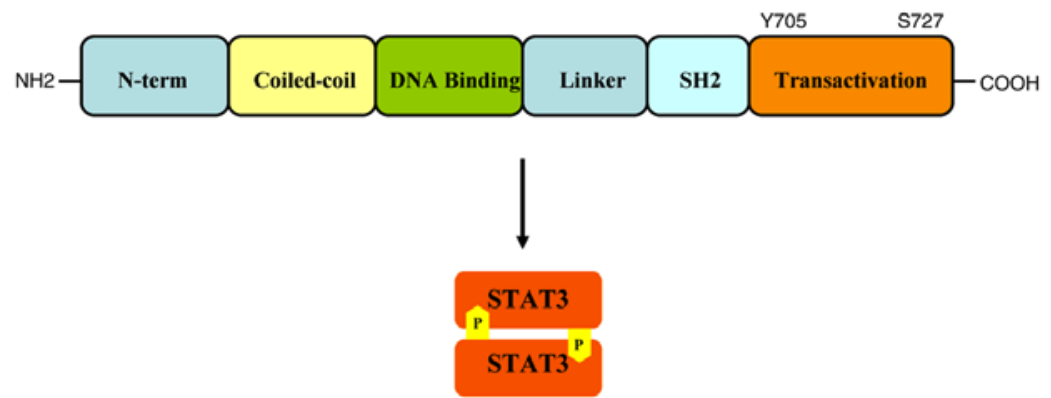

Figure 1. Structure of the STAT-3 protein. STAT-3 is comprised of of six main sections. The N-terminal domain mediates the interaction between STAT-3, promoter binding and assembly of transcriptional machinery. The coiled-coil domain promotes interactions with regulatory proteins and transcription factors. The DNA-binding domain is in direct contact with the STAT-3 regulated gene promoter. The SH-2 domain mediates dimerization via interaction with the phosphorylated Tyr705 region of a different STAT-3 monomer. The transactivation domain is responsible for the transcriptional activation of the target gene. STAT-3, signal transducer and activator of transcription-3.

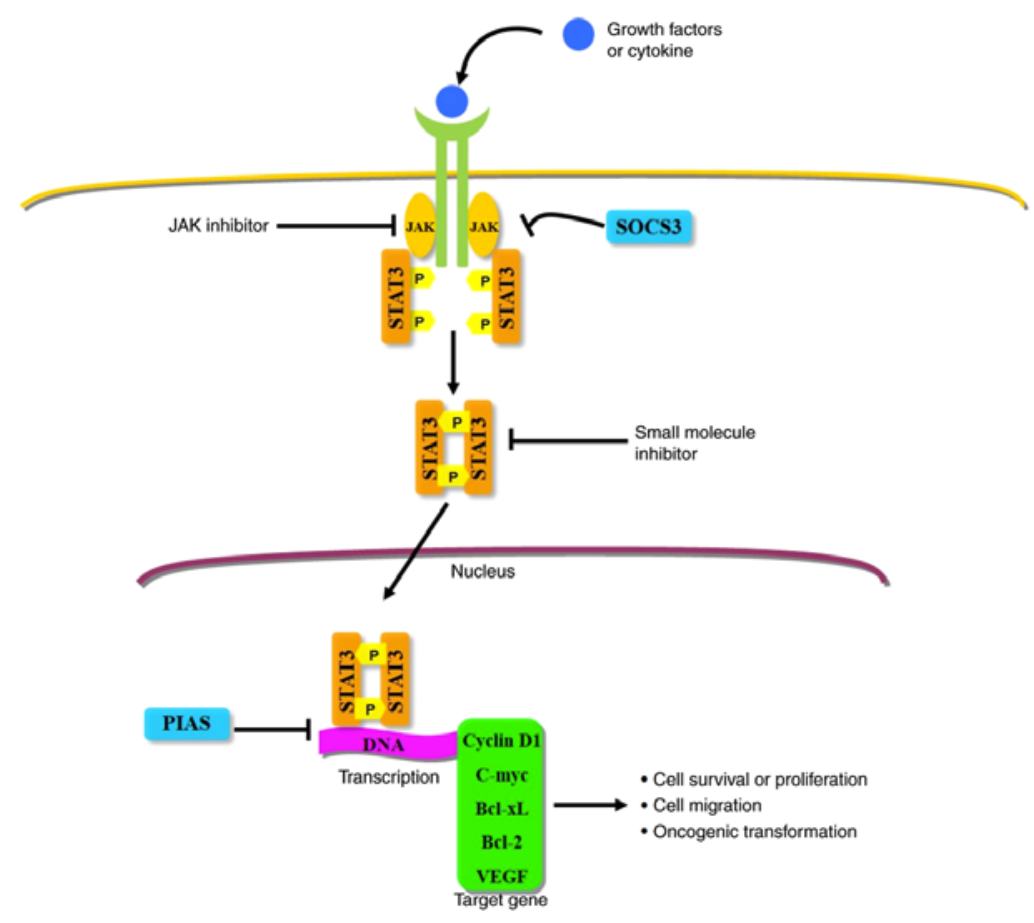

Figure 2. JAK-STAT-3 signaling pathway. Upon cytokine-mediated stimulation of the cell-surface receptor, the JAK protein on the receptor is phosphorylated and recruits STAT-3 monomers. STAT-3 binds to, and is phosphorylated by, JAK. The phosphorylated STAT- 3 then dissociates from JAK and binds cytosolic phosphorylated STAT-3 to form a dimer. The STAT-3 dimer translocates into the nucleus and promotes the transcription of downstream genes. STAT-3, signal transducer and activator of transcription-3; JAK, Janus kinase; c-Myc, MYC proto-oncogene bHLH transcription factor; Bcl-xL, BCL2-like 1; Bcl-2, BCL2 apoptosis regulator; VEGF, vascular endothelial growth factor; PIAS, protein inhibitors of activated STATs; SOCS, suppressors of cytokine signaling.

pathway and support the potential of targeting GPCRs and TLRs to inhibit STAT-3-induced tumor growth. Although numerous STAT-3-associated regulatory mechanisms mediating cancer progression have been revealed, the targeting of STAT3 in oncotherapy remains a challenge. This is due to the shallow surface pockets of STAT3 molecules, which make it difficult to form effective binding.

Additionally, inactivation can also occur via two pathways: i) The RAS/MAPK pathway; and ii) the non-receptor tyrosine kinase pathway. Mitogen-activated protein kinase (MAPK) is a serine/threonine-protein kinase and a downstream signaling molecule of the RAS pathway, which influences cell proliferation and differentiation, the inflammatory response and cell pathology. Various reports have demonstrated that RAS mediates STAT-3-induced autophagy and tumorigenesis via regulation of MAPK signaling (68-70), and that the influence of STAT-3 on gene transcription is significantly decreased following inhibition of MAPK $(71,72)$. This is due to phosphorylation of tyrosine residues during signal transduction of STAT-3 and phosphorylation of serine residues.

Independent of the JAK/STAT-3 and RAS/MAPK pathways, STAT-3 influences numerous other cytokine signal transduction pathways by interacting with molecules such as cardiotrophin-1, angiotensin II and epidermal growth factor receptor. Moreover, certain non-receptor tyrosine kinases also activate STAT-3, such as Src (37). Oncogenic Src can activate STAT-3, while BCR-ABL fusion protein can co-activate STATs $-1,-3$ and -5 (73). A recent study revealed aberrant activation of 


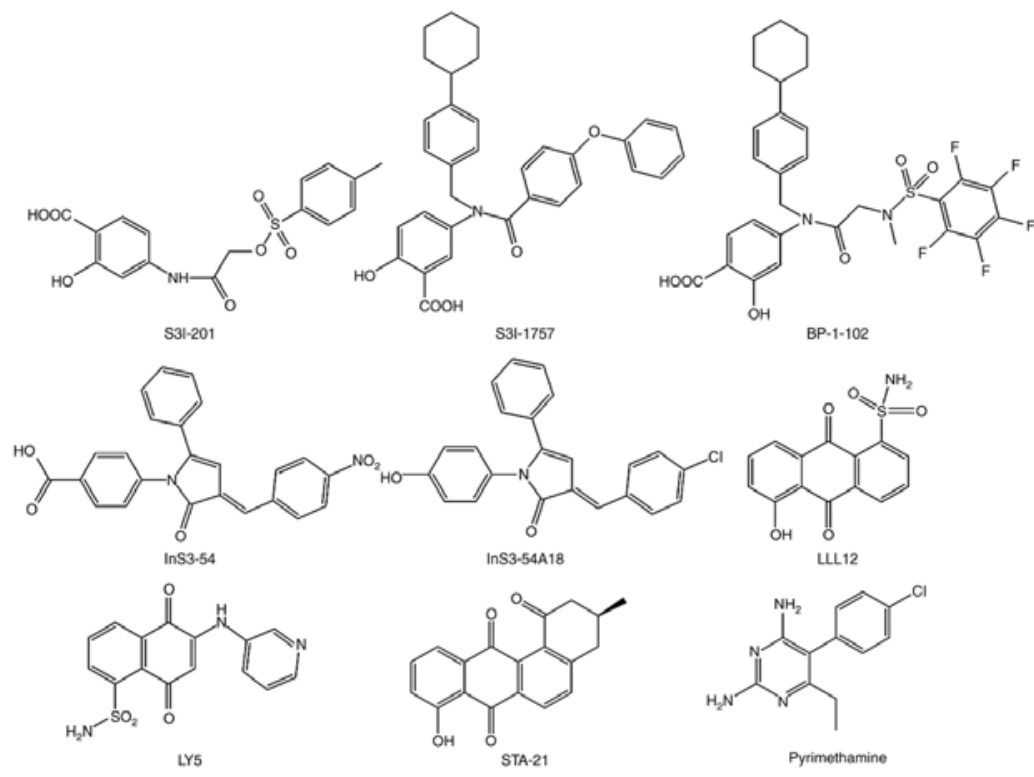

Figure 3. Chemical structures of STAT-3 inhibitors. STAT-3, signal transducer and activator of transcription-3.

STAT-3 in normal and neoplastic colorectal epithelial cells and tumor tissues with upregulated Src (74). Src homology region 2 domain-containing phosphatase 1 (SHP-1) is a non-receptor protein tyrosine phosphatase and serves as a tumor suppressor gene in numerous cancer types. Liu et al (75) demonstrated that SHP-1 expression levels are downregulated in the majority of tumor types and correlate with high expression levels of p-STAT3 expression. Thus, the SHP-1/p-STAT3 signaling axis may represent a potential therapeutic target and a clinical prognostic indicator in patients with cancer.

\section{Target genes regulated by STAT-3}

Activation of STAT-3 is transiently and rapidly sustained for a few minutes in the normal physiological state. However, persistent activation of STAT-3 can induce abnormal expression of various genes associated with cell proliferation, differentiation and apoptosis (76). Due to its significant carcinogenic properties, STAT-3 has been recognized as an oncogene. Numerous genes downstream of STAT-3 have been identified, including Mcl-1, cyclin D1, MYC proto-oncogene bHLH transcription factor (c-Myc) and vascular endothelial growth factor (77). Bcl-xL and Mcl-1 are both members of the Bcl-2 anti-apoptotic family. Bcl-xL and Bcl-2 bind Bax via $\mathrm{BH}-1$ and $\mathrm{BH}-2$, forming homologous and heterologous dimmers that influence cellular apoptosis (78). In addition, Mcl-1 inhibits the release of cytochrome $c$, which may induce the intrinsic apoptosis pathway. A recent study have demonstrated that the Bcl-xL promoter initiates transcription during the activation of STAT-3, resulting in a malignant transformation (79). Typically, cancer cells originate from healthy cells due to the combinatorial effects of various factors at different phases of cell division and growth, resulting in abnormal cell proliferation and differentiation. Notably, the cell cycle is a key aspect of this malignant transformation. STAT-3 binds Src proto-oncogene non-receptor tyrosine kinase via its SH-2 domain, activating c-myc and inducing the upregulation of cyclin D1. However, cyclin D1 and c-myc participate in the regulation of cell cycle progression, and their upregulation results in dysfunction of the cell cycle and uncontrolled cell proliferation (80). Angiogenesis is essential for cancer cell proliferation and metastasis, as it provides tumor cells with the nutrients and oxygen required for survival. Increasing evidence has indicated that persistently activated STAT-3 stimulates tumor angiogenesis (81). It has been reported that STAT-3 not only regulates the expression of VEGF in a variety of human cancer types, but that it also influences other critical angiogenic factors, including angiopoietin, matrix metallopeptidase-9, chemokine (C-X-C motif) ligand 16 and insulin-like growth factor binding protein (81-84).

\section{Advances in antitumor therapeutics targeting STAT-3}

STAT-3 is essential in various cellular processes, including the cell cycle, cell proliferation, cellular apoptosis, tumorigenesis and the regulation of the tumor niche. In healthy cells, STAT-3 activation is regulated to prevent uncontrolled gene regulation; however, abnormal activation of STAT-3 can result in the occurrence of numerous disease types (18). Increasing evidence has indicated that high-frequency abnormal activation of STAT-3 is associated with a variety of cancer types, including brain, lung, pancreatic, renal, colorectal, endometrial, cervical, ovarian, breast and prostate cancer, melanoma, glioma, head and neck squamous cell carcinoma, lymphoma and leukemia (85-87). Grivennikov et al (43) constructed a colitis-associated cancer model using mice with intestinal epithelial cell STAT-3-specific deletion and demonstrated that STAT-3-specific deletion significantly inhibits the occurrence of tumors and their progression (44). In addition, STAT-3 inhibits p53 synthesis and reduces its protective effect on genomic stability. Following the stimulation of inflammatory mediators, the probability of DNA damage and gene mutation in parenchymal cells increases significantly, and STAT-3 is also able to reduce the tolerance of ovarian cancer cells to stress and damage (67). Another study revealed that STAT-3 activates miR-608, which inhibits the proliferation, migration 
Table I. Small molecule STAT-3-activation inhibitors in clinical trials.

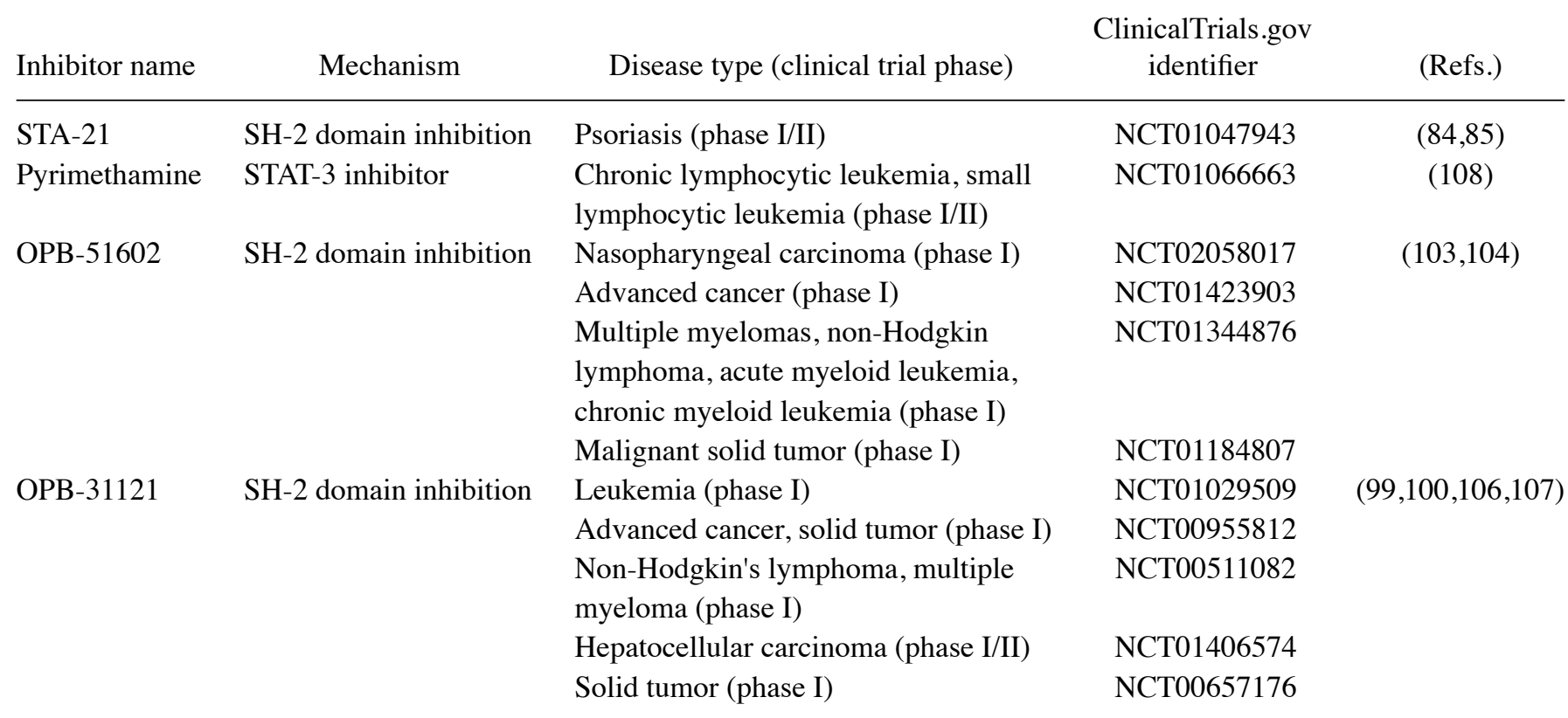

STAT-3, signal transducer and activator of transcription-3; SH-2, Src-homology-2.

and invasiveness of lung cancer cells (88). Moreover, STAT3 also serves a critical role in the regulation of tumor niche. Sun et al (89) reported that Annexin10 promotes extrahepatic cholangiocarcinoma metastasis by stimulating EMT via the STAT-3 pathway. Taken together, the aforementioned evidence indicates that persistent activation of STAT-3 contributes to cell proliferation, differentiation, migration and survival, and consequently, researchers have attempted to inhibit the STAT-3 signaling pathway as a method of cancer treatment (11-16).

In previous research, attempts were made to inhibit the effect of receptor tyrosine kinase (RTK), but mechanistic studies indicated that the inhibition of specific RTKs initiated the activation of STAT-3. Although certain small molecules targeting RTKs were used clinically, the therapeutic efficacy was limited by the development of drug resistance (90). Drug resistance represents a significant challenge for effective antitumor therapy, as it often ultimately results in treatment failure. Thus, activation of STAT-3 may contribute to the development of drug resistance; therefore, inhibition of the STAT-3 pathway can restore the efficacy of chemotherapeutics agents (91). Notably, only one compound (BBI-608) targeting STAT-3 has been approved by the Federal Drug Administration for clinical use. However, a few small molecules have been demonstrated to antagonize the STAT-3 signaling pathway (Fig. 3).

In order to target STAT-3 tyrosine phosphorylation, researchers have attempted to identify a small inhibitor molecule that directly binds the SH-2 domain of STAT-3, and prevents tyrosine phosphorylation, protein dimerization and transcriptional activity $(92,93)$. Recently, structure-based drug design and computational docking techniques have been widely used for the identification of small molecules. For example, STA-21 (deoxytetrangomycin) is an analog of tetrangomycin (a non-peptide small molecule STAT-3 inhibitor) that was discovered using structure-based drug design and has successfully completed phase I/II clinical trials $(94,95)$. Furthermore, a variety of STA-21 analogs with improved potency, including LLL-12, S-3I-201, BP-1-102 and S-3I-1757, have been demonstrated to inhibit malignant transformation, tumor cell proliferation, migration and invasion. LLL-12 is a structurally optimized analog of STA-21 and inhibits the activation of STAT-3 in a similar manner to STA-21 (96-99). Additionally, LLL-12 exerts no inhibitory effects on STAT-1 and other RTKs, indicating its specificity to STAT-3, and is more sensitive to a variety of cancer cell lines $(100,101)$. S-31-201 is another specific inhibitor of STAT-3 that inhibits STAT-3 phosphorylation and dimerization. However, molecular modeling indicated that S31-201 selectively binds to the SH-2 domain (102). Consequently, a library of S31-201 analogs has been developed and, of these, S31-201 and -1-066 exhibit potent inhibition of STAT-3 dimerization, both in vitro and in vivo $(103,104)$. Furthermore, via structure modification, BP-1-102 (an analog of SF-1-066) demonstrated improved specificity and oral bioavailability. BP-1-102 binds three locations of the STAT-3-SH-2 domain and inhibits STAT-3 activation at concentrations of 4.1-6.8 $\mu \mathrm{M}(105,106)$. In addition, certain analogs of BP-1-102 have been synthesized and evaluated to improve potency, such as SH-5-07 and -4-54 (107). These features indicate that BP-1-102 and its analogs may represent promising anticancer agents.

LY-5 is another small molecule that inhibits STAT-3 by selectively binding the major pTyr-705 region, as well as a sub-pocket of the STAT-3-SH-2 domain. LY-5 was designed by computer models using docking simulation and evaluated for inhibitory effects on STAT-3 activation and functions in human medulloblastoma cells $(108,109)$. Further studies demonstrated that LY-5 not only suppressed various cancer cells with an $\mathrm{IC}_{50}$ range of $0.5-1.4 \mu \mathrm{M}$, but that it also inhibited tumor growth in an in vivo mouse model. Furthermore, previous reports have 
demonstrated that a combination of a MEK inhibitor and LY-5 may represent a potential therapeutic strategy for overcoming resistance to MEK inhibitors in multiple human cancer cell lines $(108,109)$. Notably, further evidence has demonstrated that the SH-2 domain is an effective target for small molecule STAT-3 inhibitors. For example, it has been demonstrated that OPB-31121 and -51602 represent two potent STAT-3 inhibitors $(110,111)$. OPB-31121 and -51602 also bind to the SH-2 domain; however, molecular docking and dynamic simulations indicate that their binding site do not overlap with any other STAT-3 inhibitors $(110,111)$.

Typically, the STAT-3 SH-2 domain is considered a prime target for various STAT-3 inhibitors, due to the lack of selectivity for other domains. However, previous studies have reported that InS3-54 (designed by an improved in silico approach) effectively inhibits the STAT-3 DBD. 'In silico' refers to the use of computers to solve biological problems. In the present study, optimization and design of the lead compound were performed by simulating and calculating the interaction between receptor and ligand. This approach is known to notably improve the discovery of novel drugs (112). Notably, an optimized compound (InS3-54A18) has been identified with improved specificity and pharmacological properties, which not only inhibits STAT-3 activation via targeting the DBD of STAT-3, but also significantly inhibits the downstream target gene of STAT-3 (113-115). The aforementioned findings indicate that InS3-54A18 may be a starting point for the further development of anticancer therapeutics targeting the DBD of STAT-3.

Currently, only a few small-molecule inhibitors targeting STAT-3 are undergoing the early phases of clinical trials (Table I), and there is no inhibitor of STAT-3 approved by the FDA except BBI-608, which is a STAT-3 and cancer cell stemness inhibitor. STA-21, OPB-31121 and OPB-51602 have already completed phase I/II clinical trials in leukemia. OPB-31121 and -51602 are currently in phase I/II clinical trials for advanced solid tumors. STA-21 is not undergoing a clinical trial at present. Phase I/II studies of OPB-31121 and -51602 revealed that these compounds exert potent antitumor activities with an acceptable safety profile (116-119). Pyrimethamine is another STAT-3 inhibitor used in the treatment of chronic lymphocytic and small lymphocytic leukemia, and is currently in phase I/II clinical trials (120).

Notably, JAKs serve a crucial role in JAK/STAT-3 signaling pathway; thus, inhibiting the activity of JAKs may be a novel approach to inhibit STAT-3 activation. AG490, a JAK inhibitor, reduces the proliferation of cancer cells by inhibiting JAK-2 activity and blocking the activation of STAT-3. In addition, AG-490 has been tested in models and in clinical trials (121-123).

A range of plant-derived compounds exhibit antitumor activity against a variety of cancer types. Notably, during the previous decade, a number of STAT-3 inhibitors derived from natural sources have been employed and shown to exhibit significant efficacy in regulating STAT-3 activation. Recent studies have demonstrated that certain natural therapeutic agents serve an inhibitory role in the genesis, progression and metastasis of various cancer types (37). Betulinic acid, a pentacyclic triterpene, extracted from Zizyphus mauritiana, displayed potency in inhibiting STAT-3 activation, Src kinase, and JAK-1 and -2 (124,125). Furthermore, it has been reported that betulinic acid induces apoptosis in thyroid, breast, lung and colon carcinomas, indicating its potential as a chemotherapeutic agent (124). Furthermore, caffeic acid is a phenolic compound discovered in plants, and certain studies have reported that caffeic acid exerts potent antioxidant and anti-inflammatory properties (126-128). However, a previous study demonstrated that caffeic acid exhibits antitumor properties via the inhibition of STAT-3, preventing STAT-3 recruitment and inhibiting the formation of a transcriptional unit between STAT-3, HIF-1 $\alpha$ and p-300 on the VEGF promoter (129). Moreover, celastol, obtained from Tripterygium wilfordii, is a Chinese medicinal plant. Certain reports have indicated that celastrol can inhibit proliferation, induce apoptosis and suppress invasion/migration and angiogenesis via modulation of the DNA-binding activity of STAT-3 in a wide variety of in vitro and in vivo tumor models (130-133). In addition, a variety of agents derived from natural plants have also been demonstrated to exert antitumor effects, such as curcumin, diosgenin and honokiol derived from carcuma longa, and fenugreek and mangnolia officinalis, respectively. Furthermore, a number of reports confirmed their antitumor effects were mediated via modulation of constitutive STAT-3 activation in glioma cells, HCC cells and HepG2 cells (134-136).

\section{Conclusions}

At present, specific inhibitors of STAT-3 predominantly target the disruption of the protein-protein interactions or DNA-binding activity, such as inhibitors that prevent the recruitment of STAT-3 to the IL-6/IL-6R $\alpha / g p-130$ complex, upstream kinase inhibitors and, primarily, JAK inhibitors. Over the past decade, small-molecule drugs that directly target STAT-3 have been identified; nevertheless, there are no STAT-3-specific drugs available clinically. It has been demonstrated that STAT-3 activation promotes oncogenesis via phosphorylation or acetylation. STAT-3 inhibition has been revealed to reverse acquired resistance, synergistically inhibit tumor growth, induce apoptosis and stimulate an immune response. Therefore, this signifies a requirement to reassess ongoing strategies in order to develop clinically useful drugs. Future research should focus on the development of therapeutic molecules with STAT-3-inhibitory modalities, as this has the potential to improve the treatment of a plethora of cancer types.

\section{Acknowledgements}

Not applicable.

\section{Funding}

The present study was funded by the First Affiliated Hospital of Bengbu Medical College Science Fund for outstanding Young Scholars (grant no. 2019byyfyyq06).

\section{Availability of data and materials}

Data sharing is not applicable to this article, as no datasets were generated or analyzed during the present study. 


\section{Authors' contribution}

The paper was conceived and designed by ZL. YCG wrote the paper, and ISM revised the paper. All authors read and approved the final manuscript.

\section{Ethics approval and consent to participate}

Not applicable.

\section{Patient consent for publication}

Not applicable.

\section{Competing interests}

The authors declare that they have no competing interests.

\section{References}

1. Levy DE and Darnell JE Jr: Stats: Transcriptional control and biological impact. Nat Rev Mol Cell Biol 3: 651-662, 2002.

2. Schindler C, Levy DE and Decker T: JAK-STAT signaling: From interferons to cy tokines. J Biol Chem 282: 20059-20063, 2007.

3. Reich NC and Liu L: Tracking STAT nuclear traffic. Nat Rev Immunol 6: 602-612, 2006.

4. Stark GR and Darnell JE Jr: The JAK-STAT pathway at twenty. Immunity 36: 503-514, 2012.

5. Yu H,Pardoll D and Jove R: STATs in cancer inflammation and immunity: A leading role for STAT-3. Nat Rev Cancer 9: 798-809, 2009.

6. Bromberg J and Darnell JE Jr: The role of STATs in transcriptional control and their impact on cellular function. Oncogene 19 : 2468-2473, 2000.

7. Darnell JE Jr: STATs and gene regulation. Science 277: $1630-1635,1997$.

8. Buettner R, Mora LB and Jove R: Activated STAT signaling in human tumors provides novel molecular targets for therapeutic intervention. Clin Cancer Res 8: 945-954, 2002.

9. Yu H and Jove R: The STATs of cancer-new molecular targets come of age. Nat Rev Cancer 4: 97-105, 2004.

10. Haura EB, Turkson J and Jove R: Mechanisms of disease: Insights into the emerging role of signal transducers and activators of transcription in cancer. Nat Clin Pract Oncol 2: 315-324, 2005.

11. Herrmann A, Kortylewski M, Kujawski M,Zhang C, Reckamp K, Armstrong B, Wang L, Kowolik C, Deng J, Figlin R and Yu H: Targeting STAT3 in the myeloid compartment drastically improves the in vivo antitumor functions of adoptively transferred T cells. Cancer Res 70: 7455-7464, 2010.

12. Kortylewski $\mathrm{M}$ and $\mathrm{Yu} \mathrm{H}$ : Role of STAT-3 in suppressing anti-tumor immunity. Curr Opin Immunol 20: 228-233, 2008.

13. Kujawski M, Kortylewski M, Lee H, Herrmann A, Kay H and Yu H: STAT-3 mediates myeloid cell-dependent tumor angiogenesis in mice. J Clin Invest 118: 3367-3377, 2008.

14. Wang L, Yi T, Kortylewski M, Pardoll DM, Zeng D and Yu H: IL-17 can promote tumor growth through an IL-6-STAT-3 signaling pathway. J Exp Med 206: 1457-1464, 2009.

15. Kortylewski M, Kujawski M, Wang T, Wei S, Zhang S, Pilon-Thomas S, Niu G, Kay H, Mulé J, Kerr WG, et al: Inhibiting STAT3 signaling in the hematopoietic system elicits multicomponent antitumor immunity. Nat Med 11: 1314-1321, 2005.

16. $\mathrm{Yu} \mathrm{H}$, Kortylewski $M$ and Pardoll D: Crosstalk between cancer and immune cells: Role of STAT-3 in the tumour microenvironment. Nat Rev Immunol 7: 41-51, 2007.

17. Nowak EM, Poczeta M, Bieg D and Bednarek I: DNA methyltransferase inhibitors influence on the DIRAS3 and STAT3 expression and in vitro migration of ovarian and breast cancer cells. Ginekol Pol 88: 543-551, 2017.

18. Yu H, Lee H, Herrmann A, Buettner R and Jove R: Revisiting STAT3 signalling in cancer: New and unexpected biological functions. Nat Rev Cancer 14: 736-746, 2014.

19. Mali SB: Review of STAT3 (Signal Transducers and Activators of Transcription) in head and neck cancer. Oral Oncol 51: $565-569,2015$
20. Benekli M, Baer MR, Baumann H and Wetzler M: Signal transducer and activator of transcription proteins in leukemias. Blood 101: 2940-2954, 2003.

21. Calò V, Migliavacca M, Bazan V, Macaluso M, Buscemi M, Gebbia N and Russo A: STAT proteins: From normal control of cellular events to tumorigenesis. J Cell Physiol 197: 157-168, 2003.

22. Sternberg DW and Gilliland DG: The role of signal transducer and activator of transcription factors in leukemogenesis. J Clin Oncol 22: 361-371, 2004.

23. Abroun S, Saki N, Ahmadvand M, Asghari F, Salari F and Rahim F: STATs: An old story, yet mesmerizing. Cell J 17: 395-411, 2015.

24. Yang E, Henriksen MA, Schaefer O, Zakharova $\mathrm{N}$ and Darnell JE Jr: Dissociation time from DNA determines transcriptional function in a STAT1 linker mutant. J Biol Chem 277: 13455-13462, 2002.

25. Wake MS and Watson CJ: STAT3 the oncogene-still eluding therapy? FEBS J 282: 2600-2611, 2015.

26. Huang Y, Qiu J, Dong S, Redell MS, Poli V, Mancini MA and Tweardy DJ: Stat 3 isoforms, alpha and beta, demonstrate distinct intracellular dynamics with prolonged nuclear retention of Stat3beta mapping to its unique C-terminal end. J Biol Chem 282: 34958-34967, 2007.

27. Chakraborty A, Dyer KF, Cascio M, Mietzner TA and Tweardy DJ: Identification of a novel STAT-3 recruitment and activation motif within the granulocyte colony-stimulating factor receptor. Blood 93: 15-24, 1999.

28. Chakraborty A and Tweardy DJ: STAT-3 and G-CSF-induced myeloid differentiation. Leuk Lymphoma 30: 433-442, 1998.

29. Ilaria RL Jr: STAT isoforms: Mediators of STAT specificity or leukemogenesis? Leuk Res 25: 483-484, 2001.

30. Huynh J, Chand A, Gough D and Ernst M: Therapeutically exploiting STAT3 activity in cancer-using tissue repair as a road map. Nat Rev Cancer 19: 82-96, 2019.

31. Chai EZ, Shanmugam MK, Arfuso F, Dharmarajan A, Wang C, Kumar AP, Samy RP, Lim LH, Wang L, Goh BC, et al: Targeting transcription factor STAT3 for cancer prevention and therapy. Pharmacol Ther 162: 86-97, 2016.

32. ten Hoeve J, de Jesus Ibarra-Sanchez M, Fu Y,Zhu W, Tremblay M, David $M$ and Shuai K: Identification of a nuclear Stat1 protein tyrosine phosphatase. Mol Cell Biol 22: 5662-5668, 2002.

33. Shuai K and Liu B: Regulation of gene-activation pathways by PIAS proteins in the immune system. Nat Rev Immunol 5: 593-605, 2005.

34. Chung CD, Liao J, Liu B, Rao X, Jay P, Berta P and Shuai K: Specific inhibition of STAT-3 signal transduction by PIAS3. Science 278: 1803-1805, 1997.

35. Liu B, Gross M, ten Hoeve J and Shuai K: A transcriptional corepressor of Stat1 with an essential LXXLL signature motif. Proc Natl Acad Sci USA 98: 3203-3207, 2001.

36. Liu B, Liao J, Rao X, Kushner SA, Chung CD, Chang DD and Shuai K: Inhibition of Stat1-mediated gene activation by PIAS1. Proc Natl Acad Sci USA 95: 10626-10631, 1998.

37. Verhoeven Y, Tilborghs S, Jacobs J, De Waele J, Quatannens D, Deben C, Prenen H, Pauwels P, Trinh XB, Wouters A, et al: The potential and controversy of targeting STAT family members in cancer. Semin Cancer Biol: Oct 9, 2019 doi: 10.1016/j. semcancer.2019.10.002 (Epub ahead of print).

38. Catlett-Falcone R, Landowski TH, Oshiro MM, Turkson J, Levitzki A, Savino R, Ciliberto G, Moscinski L, Fernández-Luna JL, Nuñez G, et al: Constitutive activation of STAT3 signaling confers resistance to apoptosis in human U266 myeloma cells. Immunity 10: 105-115, 1999.

39. Huynh J, Etemadi N, Hollande F, Ernst M and Buchert M: The JAK/STAT3 axis: A comprehensive drug target for solid malignancies. Semin Cancer Biol 45: 13-22, 2017.

40. Johnson DE, O'Keefe RA and Grandis JR: Targeting the IL-6/JAK/STAT3 signalling axis in cancer. Nat Rev Clin Oncol 15: 234-248, 2018.

41. Park EJ, Lee JH, Yu GY, He G, Ali SR, Holzer RG, Osterreicher $\mathrm{CH}$, Takahashi $\mathrm{H}$ and Karin M: Dietary and genetic obesity promote liver inflammation and tumorigenesis by enhancing IL-6 and TNF expression. Cell 140: 197-208, 2010.

42. Jones SA, Scheller J and Rose-John S: Therapeutic strategies for the clinical blockade of IL-6/gp130 signaling. J Clin Invest 121: 3375-3383, 2011.

43. Grivennikov S, Karin E, Terzic J, Mucida D, Yu GY, Vallabhapurapu S, Scheller J, Rose-John S, Cheroutre H, Eckmann L and Karin M: IL-6 and STAT3 are required for survival of intestinal epithelial cells and development of colitis-associated cancer. Cancer Cell 15: 103-113, 2009. 
44. Bollrath J, Phesse TJ, von Burstin VA, Putoczki T, Bennecke M, Bateman T, Nebelsiek T, Lundgren-May T, Canli O, Schwitalla S, et al: Gp130-mediated STAT3 activation in enterocytes regulates cell survival and cell-cycle progression during colitis-associated tumorigenesis. Cancer Cell 15: 91-102, 2009.

45. Schiechl G, Bauer B, Fuss I, Lang SA, Moser C, Ruemmele P, Rose-John S, Neurath MF, Geissler EK, Schlitt HJ, et al: Tumor development in murine ulcerative colitis depends on MyD88 signaling of colonic $\mathrm{F} 4 / 80+\mathrm{CD} 11 \mathrm{~b}$ (high)Gr1(low) macrophages J Clin Invest 121: 1692-1708, 2011.

46. Zhang L, Yang J, Qian J, Li H, Romaguera JE, Kwak LW, Wang $\mathrm{M}$ and Yi Q: Role of the microenvironment in mantle cell lymphoma: IL-6 is an important survival factor for the tumor cells. Blood 120: 3783-3792, 2012.

47. Schafer ZT and Brugge JS: IL-6 involvement in epithelial cancers. J Clin Invest 117: 3660-3663, 2007.

48. Sansone P, Storci G, Tavolari S, Guarnieri T, Giovannini C, Taffurelli M, Ceccarelli C, Santini D, Paterini P, Marcu KB, et al: IL-6 triggers malignant features in mammospheres from human ductal breast carcinoma and normal mammary gland. J Clin Invest 117: 3988-4002, 2007.

49. Pine SR, Mechanic LE, Enewold L, Chaturvedi AK, Katki HA, Zheng YL, Bowman ED, Engels EA, Caporaso NE and Harris CC: Increased levels of circulating interleukin 6, interleukin 8, C-reactive protein, and risk of lung cancer. J Natl Cancer Inst 103: 1112-1122, 2011.

50. Nakashima J, Tachibana M, Horiguchi Y, Oya M, Ohigashi T, Asakura $\mathrm{H}$ and Murai M: Serum interleukin 6 as a prognostic factor in patients with prostate cancer. Clin Cancer Res 6 : 2702-2706, 2000.

51. Reynaud D, Pietras E, Barry-Holson K, Mir A, Binnewies M, Jeanne M, Sala-Torra O, Radich JP and Passegué E: IL-6 controls leukemic multipotent progenitor cell fate and contributes to chronic myelogenous leukemia development. Cancer Cell 20: 661-673, 2011

52. Ancrile B, Lim KH and Counter CM: Oncogenic Ras-induced secretion of IL6 is required for tumorigenesis. Genes Dev 21: 1714-1719, 2007.

53. Gyamfi J, Lee YH, Eom M and Choi J: Interleukin-6/STAT3 signalling regulates adipocyte induced epithelial-mesenchyma transition in breast cancer cells. Sci Rep 8: 8859, 2018.

54. Gao X, Liu X, Lu Y, Wang Y, Cao W, Liu X, Hu H and Wang H: PIM1 is responsible for IL-6-induced breast cancer cell EMT and stemness via c-myc activation. Breast Cancer 26: 663-671, 2019.

55. Kim MS, Lee WS, Jeong J, Kim SJ and Jin W: Induction of metastatic potential by TrkB via activation of IL6/JAK2/STAT3 and PI3K/AKT signaling in breast cancer. Oncotarget 6 : 40158-40171, 2015.

56. Xin H, Lu R, Lee H, Zhang W, Zhang C, Deng J, Liu Y, Shen S, Wagner KU, Forman S, et al: G-protein-coupled receptor agonist BV8/prokineticin-2 and STAT3 protein form a feed-forward loop in both normal and malignant myeloid cells. J Biol Chem 288: 13842-13849, 2013.

57. Lee H, Deng J, Kujawski M, Yang C, Liu Y, Herrmann A, Kortylewski M, Horne D, Somlo G, Forman S, et al: STAT-3-induced S1PR1 expression is crucial for persistent STAT-3 activation in tumors. Nat Med 16: 1421-1428, 2010.

58. Visentin B, Vekich JA, Sibbald BJ, Cavalli AL, Moreno KM, Matteo RG, Garland WA, Lu Y, Yu S, Hall HS, et al: Validation of an anti-sphingosine-1-phosphate antibody as a potential therapeutic in reducing growth, invasion, and angiogenesis in multiple tumor lineages. Cancer Cell 9: 225-238, 2006.

59. Kawamori T, Kaneshiro T, Okumura M, Maalouf S, Uflacker A, Bielawski J, Hannun YA and Obeid LM: Role for sphingosine kinase 1 in colon carcinogenesis. FASEB J 23: 405-414, 2009.

60. Sarkar S, Maceyka M, Hait NC, Paugh SW, Sankala H, Milstien S and Spiegel S: Sphingosine kinase 1 is required for migration, proliferation and survival of MCF-7 human breast cancer cells. FEBS Lett 579: 5313-5317, 2005.

61. Liu Y, Deng J, Wang L, Lee H, Armstrong B, Scuto A, Kowolik C, Weiss LM, Forman S and Yu H: S1PR1 is an effective target to block STAT-3 signaling in activated B cell-like diffuse large B-cell lymphoma. Blood 120: 1458-1465, 2012.

62. Ponnusamy S, Meyers-Needham M, Senkal CE, Saddoughi SA, Sentelle D, Selvam SP, Salas A and Ogretmen B: Sphingolipids and cancer: Ceramide and sphingosine-1-phosphate in the regulation of cell death and drug resistance. Future Oncol 6 : 1603-1624, 2010.

63. Priceman SJ, Shen S, Wang L, Deng J, Yue C, Kujawski M and $\mathrm{Yu} \mathrm{H}$ : S1PR1 is crucial for accumulation of regulatory T cells in tumors via STAT3. Cell Rep 6: 992-999, 2014.
64. Eyking A, Ey B, Rünzi M, Roig AI, Reis H, Schmid KW, Gerken G, Podolsky DK and Cario E: Toll-like receptor 4 variant D299G induces features of neoplastic progression in Caco-2 intestinal cells and is associated with advanced human colon cancer. Gastroenterology 141: 2154-2165, 2011.

65. Tye H, Kennedy CL, Najdovska M, McLeod L, McCormack W, Hughes N, Dev A, Sievert W, Ooi CH, Ishikawa TO, et al: STAT-3-driven upregulation of TLR2 promotes gastric tumorigenesis independent of tumor inflammation. Cancer Cell 22: 466-478, 2012.

66. Ochi A, Graffeo CS, Zambirinis CP, Rehman A, Hackman M, Fallon N, Barilla RM, Henning JR, Jamal M, Rao R, et al: Toll-like receptor 7 regulates pancreatic carcinogenesis in mice and humans. J Clin Invest 122: 4118-4129, 2012.

67. Wild CA, Brandau S, Lindemann M, Lotfi R, Hoffmann TK, Lang $\mathrm{S}$ and Bergmann C: Toll-like receptors in regulatory $\mathrm{T}$ cells of patients with head and neck cancer. Arch Otolaryngol Head Neck Surg 136: 1253-1259, 2010.

68. Liang F, Ren C, Wang J, Wang S, Yang L, Han X, Chen Y, Tong $\mathrm{G}$ and Yang G: The crosstalk between STAT3 and p53/RAS signaling controls cancer cell metastasis and cisplatin resistance via the Slug/MAPK/PI3K/AKTmediated regulation of EMT and autophagy. Oncogenesis 8: 59, 2019.

69. Wang JR, Shen GN, Luo YH, Piao XJ, Zhang Y, Wang H, Li JQ, Xu WT,Zhang Y, Wang SN, et al: 2-(4-methoxyphenylthio)-5,8-dimethoxy-1,4-naphthoquinone induces apoptosis via ROS-mediated MAPK and STAT3 signaling pathway in human gastric cancer cells. J Chemother 31: 214-226, 2019.

70. Lakshmanachetty S, Balaiya V, High WA and Koster MI: Loss of TP63 promotes the metastasis of head and neck squamous cell carcinoma by activating MAPK and STAT3 signaling. Mol Cancer Res 17: 1279-1293, 2019.

71. Ahmed ST and Ivashkiv LB: Inhibition of IL-6 and IL-10 signaling and Stat activation by inflammatory and stress pathways. J Immunol 165: 5227-5237, 2000

72. Yan K, Xu X, Wu T, Li J, Cao G, Li Y and Ji Z: Knockdown of PYCR1 inhibits proliferation, drug resistance and EMT in colorectal cancer cells by regulating STAT3-Mediated p38 MAPK and NF-kB signalling pathway. Biochem Biophys Res Commun 520: 486-491, 2019.

73. Benekli $\mathrm{M}$, Baumann $\mathrm{H}$ and Wetzler $\mathrm{M}$ : Targeting signal transducer and activator of transcription signaling pathway in leukemias. J Clin Oncol 27: 4422-4432, 2009.

74. Zhang S, Yang Z, Bao W, Liu L, You Y, Wang X, Shao L, Fu W, Kou X, Shen W, et al: SNX10 (sorting nexin 10) inhibits colorectal cancer initiation and progression by controlling autophagic degradation of SRC. Autophagy 4: 1-15, 2019.

75. Liu CY, Huang TT, Chu PY, Huang CT, Lee CH, Wang WL, Lau KY, Tsai WC, Chao TI, Su JC, et al: The tyrosine kinase inhibitor nintedanib activates SHP-1 and induces apoptosis in triple-negative breast cancer cells. Exp Mol Med 49: e366, 2017.

76. Yu H, Pardoll D and Jove R: STATs in cancer inflammation and immunity: A leading role for STAT3. Nat Rev Cancer 9: 798-809, 2009.

77. Jarnicki A, Putoczki T and Ernst M: Stat3: Linking inflammation to epithelial cancer-more than a 'gut' feeling? Cell Div 5: $14,2010$.

78. Siveen KS, Sikka S, Surana R, Dai X, Zhang J, Kumar AP, Tan BK, Sethi G and Bishayee A: Targeting the STAT3 signaling pathway in cancer: Role of synthetic and natural inhibitors. Biochim Biophys Acta 1845: 136-154, 2014.

79. Huang DC, Adams JM and Cory S: The conserved N-terminal BH4 domain of Bcl-2 homologues is essential for inhibition of apoptosis and interaction with CED-4. EMBO J 17: 1029-1039, 1998.

80. Reed JC: Mechanisms of apoptosis avoidance in cancer. Curr Opin Oncol 11: 68-75, 1999.

81. Welcker M, Lukas J, Strauss M and Bartek J: Enhanced protein stability: A novel mechanism of D-type cyclin over-abundance identified in human sarcoma cells. Oncogene 13: 419-425, 1996.

82. Wei D, Le X, Zheng L, Wang L, Frey JA, Gao AC, Peng Z, Huang S, Xiong HQ, Abbruzzese JL and Xie K: STAT-3 activation regulates the expression of vascular endothelial growth factor and human pancreatic cancer angiogenesis and metastasis. Oncogene 22: 319-329, 2003

83. Dechow TN, Pedranzini L, Leitch A, Leslie K, Gerald WL, Linkov I and Bromberg JF: Requirement of matrix metalloproteinase-9 for the transformation of human mammary epithelial cells by STAT-3-C. Proc Natl Acad Sci USA 101: 10602-10607, 2004. 
84. Niu G, Wright KL, Huang M, Song L, Haura E, Turkson J, Zhang S, Wang T, Sinibaldi D, Coppola D, et al: Constitutive STAT-3 activity up-regulates VEGF expression and tumor angiogenesis. Oncogene 21: 2000-2008, 2002.

85. Lieblein JC, Ball S, Hutzen B, Sasser AK, Lin HJ, Huang TH, Hall BM and Lin J: STAT3 can be activated through paracrine signaling in breast epithelial cells. BMC Cancer 8: 302, 2008.

86. Lin J, Jin X, Rothman K, Lin HJ, Tang H and Burke W: Modulation of signal transducer and activator of transcription 3 activities by 53 tumor suppressor in breast cancer cells. Cancer Res 62: 376-380, 2002.

87. Li L, Tang W, Wu X, Karnak D, Meng X, Thompson R, Hao X, Li Y, Qiao XT, Lin J, et al: HAb18G/CD147 promotes pSTAT-3-mediated pancreatic cancer development via CD44s. Clin Cancer Res 19: 6703-6715, 2013.

88. Xu W, Sun D, Wang Y, Zheng X, Li Y, Xia Y and Teng Y: Inhibitory effect of microRNA-608 on lung cancer cell proliferation, migration, and invasion by targeting BRD4 through the JAK2/STAT3 pathway. Bosn J Basic Med Sci: Oct 17, 2019 doi 10.17305/bjbms.2019.4216 (Epub ahead of print).

89. Sun R, Liu Z, Qiu B, Chen T, Li Z, Zhang X, Xu Y and Zhang Z: Annexin10 promotes extrahepatic cholangiocarcinoma metastasis by facilitating EMT via PLA2G4A/PGE2/STAT3 pathway. EBioMedicine 47: 142-155, 2019.

90. Sun C and Bernards R: Feedback and redundancy in receptor tyrosine kinase signaling: Relevance to cancer therapies. Trends Biochem Sci 39: 465-474, 2014

91. Li G, Zhao L, Li W, Fan K, Qian W, Hou S, Wang H, Dai J, Wei $\mathrm{H}$ and Guo Y: Feedback activation of STAT3 mediates trastuzumab resistance via upregulation of MUC1 and MUC4 expression. Oncotarget 5: 8317-8329, 2014.

92. Song H, Wang R, Wang S and Lin J: A low-molecular-weight compound discovered through virtual database screening inhibits STAT-3 function in breast cancer cells. Proc Natl Acad Sci USA 102: 4700-4705, 2005.

93. Chen CL, Cen L, Kohout J, Hutzen B, Chan C, Hsieh FC, Loy A Huang V, Cheng G and Lin J: Signal transducer and activator of transcription 3 activation is associated with bladder cancer cell growth and survival. Mol Cancer 7: 78, 2008.

94. Miyoshi K, Takaishi M, Nakajima K, Ikeda M, Kanda T, Tarutani M, Iiyama T, Asao N, DiGiovanni J and Sano S: STAT3 as a therapeutic target for the treatment of psoriasis: A clinical feasibility study with STA-21, a STAT3 inhibitor. J Invest Dermatol 131: 108-117, 2011

95. Park JS, Kwok SK, Lim MA, Kim EK, Ryu JG, Kim SM, Oh HJ, Ju JH, Park SH, Kim HY and Cho ML: STA-21, a promising STAT-3 inhibitor that reciprocally regulates Th17 and Treg cells, inhibits osteoclastogenesis in mice and humans and alleviates autoimmune inflammation in an experimental model of rheumatoid arthritis. Arthritis Rheumatol 66: 918-929, 2014

96.Lin L, Liu A, Peng Z, Lin HJ, Li PK, Li C and Lin J: STAT-3 is necessary for proliferation and survival in colon cancer-initiating cells. Cancer Res 71: 7226-7237, 2011

97. Lin L, Benson DM Jr, DeAngelis S, Bakan CE, Li PK, Li C and Lin J: A small molecule, LLL12 inhibits constitutive STAT-3 and IL-6-induced STAT-3 signaling and exhibits potent growth suppressive activity in human multiple myeloma cells. Int J Cancer 130: 1459-1469, 2012.

98. Liu Y, Li PK, Li C and Lin J: Inhibition of STAT-3 signaling blocks the anti-apoptotic activity of IL-6 in human liver cancer cells. J Biol Chem 285: 27429-27439, 2010.

99. Jain R, Kulkarni P, Dhali S, Rapole S and Srivastava S: Quantitative proteomic analysis of global effect of LLL12 on U87 cell's proteome: An insight into the molecular mechanism of LLL12. J Proteomics 113: 127-142, 2015.

100.Zuo M, Li C, Lin J and Javle M: LLL12, a novel small inhibitor targeting STAT-3 for hepatocellular carcinoma therapy. Oncotarget 6: 10940-10949,2015.

101. Bid HK, Kibler A, Phelps DA, Manap S, Xiao L, Lin J, Capper D, Oswald D, Geier B, DeWire M, et al: Development, characterization, and reversal of acquired resistance to the MEK1 inhibitor selumetinib (AZD6244) in an in vivo model of childhood astrocytoma. Clin Cancer Res 19: 6716-6729, 2013.

102. Siddiquee K, Zhang S, Guida WC, Blaskovich MA, Greedy B, Lawrence HR, Yip ML, Jove R, McLaughlin MM, Lawrence NJ, et al: Selective chemical probe inhibitor of STAT3, identified through structure-based virtual screening, induces antitumor activity. Proc Natl Acad Sci USA 104: 7391-7396, 2007.
103. Zhang X, Yue P, Fletcher S, Zhao W, Gunning PT and Turkson J: A novel small-molecule disrupts STAT-3 SH2 domain-phosphotyrosine interactions and STAT-3-dependent tumor processes. Biochem Pharmacol 79: 1398-1409, 2010

104. Fletcher S, Singh J, Zhang X, Yue P, Page BD, Sharmeen S, Shahani VM, Zhao W, Schimmer AD, Turkson J and Gunning PT: Disruption of transcriptionally active Stat 3 dimers with non-phosphorylated, salicylic acid-based small molecules: Potent in vitro and tumor cell activities. Chembiochem 10: 1959-1964, 2009.

105. Zhang X, Yue P, Page BD, Li T, Zhao W, Namanja AT, Paladino D, Zhao J, Chen Y, Gunning PT and Turkson J: Orally bioavailable small-molecule inhibitor of transcription factor Stat-3 regresses human breast and lung cancer xenografts. Proc Natl Acad Sci USA 109: 9623-9628, 2012.

106. Resetca D, Haftchenary S, Gunning PT and Wilson DJ: Changes in signal transducer and activator of transcription 3 (STAT-3) dynamics induced by complexation with pharmacological inhibitors of Src homology 2 (SH2) domain dimerization. J Biol Chem 289: 32538-32547, 2014

107. Haftchenary S, Luchman HA, Jouk AO, Veloso AJ, Page BD, Cheng XR, Dawson SS, Grinshtein N, Shahani VM, Kerman K, et al: Potent targeting of the STAT 3 protein in brain cancer stem cells: A promising route for treating glioblastoma. ACS Med Chem Lett 4: 1102-1107, 2013.

108. Zhao C, Xiao H, Wu X, Li C, Liang G, Yang S and Lin J: Rational combination of MEK inhibitor and the STAT-3 pathway modulator for the therapy in K-Ras mutated pancreatic and colon cancer cells. Oncotarget 6: 14472-14487, 2015

109. Xiao H, Bid HK, Jou D, Wu X, Yu W, Li C, Houghton PJ and Lin J: A novel small molecular STAT-3 inhibitor, LY5, inhibits cell viability, cell migration, and angiogenesis in medulloblastoma cells. J Biol Chem 290: 3418-3429, 2015.

110. Hayakawa F, Sugimoto K, Harada Y, Hashimoto N, Ohi N, Kurahashi S and Naoe T: A novel STAT inhibitor, OPB-31121, has a significant antitumor effect on leukemia with STAT-addictive oncokinases. Blood Cancer J 3: e166, 2013.

111. Kim MJ, Nam HJ, Kim HP, Han SW, Im SA, Kim TY, Oh DY and Bang YJ: OPB-31121, a novel small molecular inhibitor, disrupts the JAK2/STAT-3 pathway and exhibits an antitumor activity in gastric cancer cells. Cancer Lett 335: 145-152, 2013.

112. Yu W, Xiao H, Lin J and Li C: Discovery of novel STAT3 small molecule inhibitors via in silico site-directed fragment-based drug design. J Med Chem 56: 4402-4412, 2013.

113. Huang W, Dong Z, Chen Y, Wang F, Wang CJ, Peng H, He Y, Hangoc G, Pollok K, Sandusky G, et al: Small-molecule inhibitors targeting the DNA-binding domain of STAT-3 suppress tumor growth, metastasis and STAT-3 target gene expression in vivo. Oncogene $35: 802,2016$

114. Huang W, Dong Z, Wang F, Peng H, Liu JY and Zhang JT: A small molecule compound targeting STAT-3 DNA-binding domain inhibits cancer cell proliferation, migration, and invasion. ACS Chem Biol 9: 1188-1196, 2014.

115. Ogura M, Uchida T, Terui Y, Hayakawa F, Kobayashi Y, Taniwaki M, Takamatsu Y, Naoe T, Tobinai K, Munakata W, et al: Phase I study of OPB-51602, an oral inhibitor of signal transducer and activator of transcription 3 , in patients with relapsed/refractory hematological malignancies. Cancer Sci 106: 896-901, 2015.

116. Wong AL, Soo RA, Tan DS, Lee SC, Lim JS, Marban PC, Kong LR, Lee YJ, Wang LZ, Thuya WL, et al: Phase I and biomarker study of OPB-51602, a novel signal transducer and activator of transcription (STAT) 3 inhibitor, in patients with refractory solid malignancies. Ann Oncol 26: 998-1005, 2015.

117. Brambilla L, Genini D, Laurini E, Merulla J, Perez L, Fermeglia M, Carbone GM, Pricl S and Catapano CV: Hitting the right spot: Mechanism of action of OPB-31121, a novel and potent inhibitor of the Signal Transducer and Activator of Transcription 3 (STAT-3). Mol Oncol 9: 1194-1206, 2015.

118. Oh DY, Lee SH, Han SW, Kim MJ, Kim TM, Kim TY Heo DS, Yuasa M, Yanagihara Y and Bang YJ: Phase I study of OPB-31121, an Oral STAT-3 inhibitor, in patients with advanced solid tumors. Cancer Res Treat 47: 607-615, 2015.

119. Okusaka T, Ueno H, Ikeda M, Mitsunaga S, Ozaka M, Ishii H, Yokosuka O, Ooka Y, Yoshimoto R, Yanagihara Y and Okita K: Phase 1 and pharmacological trial of OPB-31121, a signal transducer and activator of transcription-3 inhibitor in patients with advanced hepatocellular carcinoma. Hepatol Res 45: 1283-1291, 2015.

120. Takakura A, Nelson EA, Haque N, Humphreys BD, Zandi-Nejad K, Frank DA and Zhou J: Pyrimethamine inhibits adult polycystic kidney disease by modulating STAT signaling pathways. Hum Mol Genet 20: 4143-4154, 2011. 
121. Meydan N, Grunberger T, Dadi H, Shahar M, Arpaia E, Lapidot Z, Leeder JS, Freedman M, Cohen A, Gazit A, et al: Inhibition of acute lymphoblastic leukaemia by a Jak-2 inhibitor. Nature 379: 645-648, 1996.

122. Jin J, Guo Q, Xie J, Jin D and Zhu Y: Combination of MEK inhibitor and the JAK2-STAT3 pathway inhibition for the therapy of colon cancer. Pathol Oncol Res 25: 769-775, 2019.

123. Joung YH, Na YM, Yoo YB, Darvin P, Sp N, Kang DY, Kim SY, Kim HS, Choi YH, Lee HK, et al: Combination of AG490, a Jak2 inhibitor, and methylsulfonylmethane synergistically suppresses bladder tumor growth via the Jak2/STAT3 pathway. Int J Oncol 44: 883-895, 2014.

124. Pandey MK, Sung B and Aggarwal BB: Betulinic acid suppresses STAT-3 activation pathway through induction of protein tyrosine phosphatase SHP-1 in human multiple myeloma cells. Int J Cancer 127: 282-292, 2010.

125. Su D, Gao YQ, Dai WB, Hu Y, Wu YF and Mei QX: Helicteric acid, oleanic acid, and betulinic acid, three triterpenes from helicteres angustifolia L., Inhibit proliferation and induce apoptosis in HT-29 colorectal cancer cells via suppressing NF- $\kappa$ B and STAT3 signaling. Evid Based Complement Alternat Med 2017: 5180707, 2017.

126. Nardini M, Pisu P, Gentili V, Natella F, Di Felice M, Piccolella E and Scaccini C: Effect of caffeic acid on tert-butyl hydroperoxide-induced oxidative stress in U937. Free Radic Biol Med 25: 1098-1105, 1998.

127. Tapiero H, Tew KD, Ba GN and Mathe G: Polyphenols: Do they play a role in the prevention of human pathologies? Biomed Pharmacother 56: 200-207, 2002.

128. Nardini M, Leonardi F, Scaccini C and Virgili F: Modulation of ceramide-induced NF-kappaB binding activity and apoptotic response by caffeic acid in U937 cells: Comparison with other antioxidants. Free Radic Biol Med 30: 722-733, 2001

129. Jung JE, Kim HS, Lee CS, Park DH, Kim YN, Lee MJ, Lee JW, Park JW, Kim MS, Ye SK and Chung MH: Caffeic acid and its synthetic derivative CADPE suppress tumor angiogenesis by blocking STAT-3-mediated VEGF expression in human renal carcinoma cells. Carcinogenesis 28: 1780-1787, 2007.
130. Rajendran P, Li F, Shanmugam MK, Kannaiyan R, Goh JN, Wong KF, Wang W, Khin E, Tergaonkar V, Kumar AP, et al: Celastrol suppresses growth and induces apoptosis of human hepatocellular carcinoma through the modulation of STAT-3/JAK2 signaling cascade in vitro and in vivo. Cancer Prev Res (Phila) 5: 631-643, 2012.

131. Kannaiyan R, Hay HS, Rajendran P, Li F, Shanmugam MK, Vali S, Abbasi T, Kapoor S, Sharma A, Kumar AP, et al: Celastrol inhibits proliferation and induces chemosensitization through down-regulation of NF-KB and STAT-3 regulated gene products in multiple myeloma cells. Br J Pharmacol 164: 1506-1521, 2011.

132. Pang X, Yi Z, Zhang J, Lu B, Sung B, Qu W, Aggarwal BB and Liu M: Celastrol suppresses angiogenesis-mediated tumor growth through inhibition of AKT/mammalian target of rapamycin pathway. Cancer Res 70: 1951-1959, 2010.

133. Lu Z, Jin Y, Qiu L, Lai Y and Pan J: Celastrol, a novel HSP90 inhibitor, depletes Bcr-Abl and induces apoptosis in imatinib-resistant chronic myelogenous leukemia cells harboring T315I mutation. Cancer Lett 290: 182-191, 2010.

134. Weissenberger J, Priester M, Bernreuther C, Rakel S, Glatzel M, Seifert V and Kögel D: Dietary curcumin attenuates glioma growth in a syngeneic mouse model by inhibition of the JAK1,2/STAT-3 signaling pathway. Clin Cancer Res 16: 5781-5795, 2010.

135. Li F, Fernandez PP, Rajendran P, Hui KM and Sethi G: Diosgenin, a steroidal saponin, inhibits STAT-3 signaling pathway leading to suppression of proliferation and chemosensitization of human hepatocellular carcinoma cells. Cancer Lett 292: 197-207, 2010.

136. Rajendran P, Li F, Shanmugam MK, Vali S, Abbasi T, Kapoor S, Ahn KS, Kumar AP and Sethi G: Honokiol inhibits signal transducer and activator of transcription-3 signaling, proliferation, and survival of hepatocellular carcinoma cells via the protein tyrosine phosphatase SHP-1. J Cell Physiol 227: 2184-2195, 2012. International (CC BY-NC-ND 4.0) License. 